\title{
Un étrange sinus « pilonidal » ...
}

\author{
A. Senéjoux \\ (C) Lavoisier SAS 2015
}

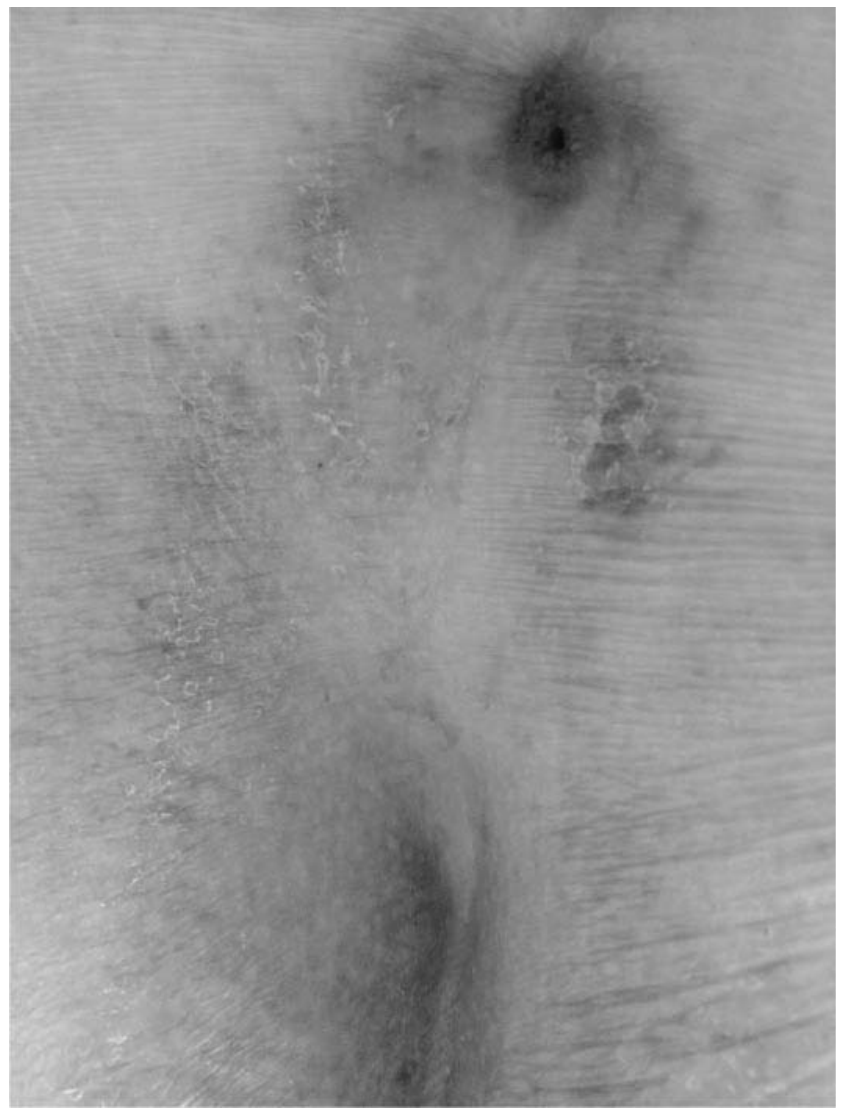

Fig. 1 Suppuration située au niveau de la partie haute du sillon interfessier

\section{Observation}

Une femme âgée de 89 ans était adressée en consultation de proctologie par le médecin de l'EHPAD où elle réside depuis une dizaine d'années.

En effet depuis 2 ans elle présente une suppuration située au niveau de la partie haute du sillon interfessier sous la

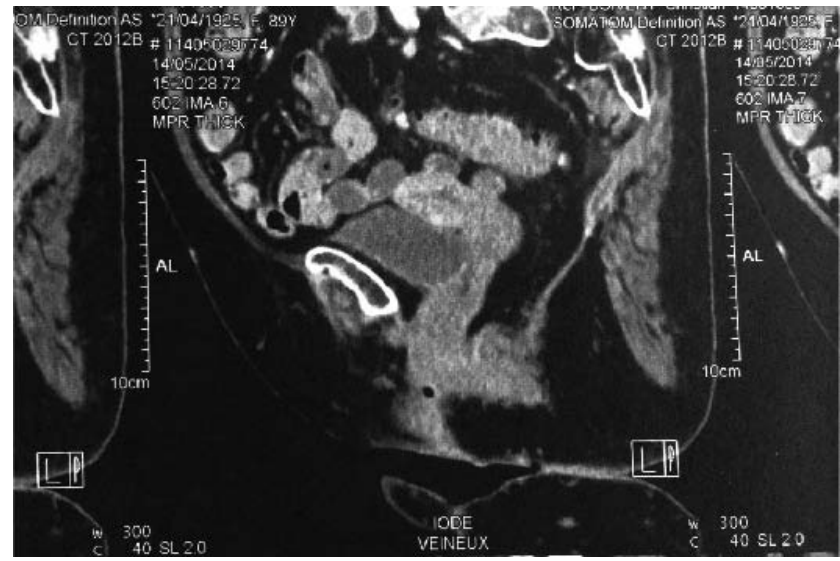

Fig. 2 Scanner

forme d'un orifice de petite taille, indolore mais régulièrement productif (Fig. 1). Il n’y a pas de douleur locale.

Des soins locaux sont réalisés depuis plusieurs mois sans succès.

Le médecin traitant adresse cette patiente pour prise en charge d'une suspicion de sinus pilonidal.

\section{Quel est votre diagnostic ?}

Il s'agissait en fait d'une pathologie diverticulaire fistulisée au sillon interfessier.

Compte tenu du mauvais état général de la patiente aucun geste chirurgical n'a pu être réalisé.

Devant cette suppuration chronique du sillon interfessier, en l'absence de fossette médiane évocatrice d'une maladie pilonidale et compte tenu du caractère franchement inhabituel de cette pathologie à cet âge un scanner a été réalisé (Fig. 2).

\footnotetext{
A. Senéjoux $(\square)$

Centre Hospitalier Privé Rennes Saint Grégoire,

6 bd de la Boutière, 35760 Saint Grégoire

e-mail : agnes.senejoux@gmail.com
} 